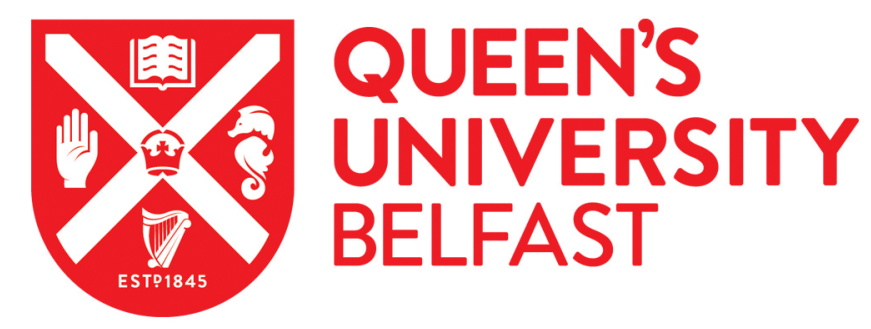

\title{
Spiral Antenna with Reconfigurable HIS using Liquid Crystals for Monopulse Radar Application
}

Mohamad, S., \& Cahill, R. (2018). Spiral Antenna with Reconfigurable HIS using Liquid Crystals for Monopulse Radar Application. In IEEE Conference on Antenna Measurements \& Applications (CAMA), 4-6th Dec 2017 (pp. 55-58) https://doi.org/10.1109/CAMA.2017.8273476

\section{Published in:}

IEEE Conference on Antenna Measurements \& Applications (CAMA), 4-6th Dec 2017

\section{Document Version:}

Peer reviewed version

Queen's University Belfast - Research Portal:

Link to publication record in Queen's University Belfast Research Portal

\section{Publisher rights}

(C) 2017 IEEE.

This work is made available online in accordance with the publisher's policies. Please refer to any applicable terms of use of the publisher.

\section{General rights}

Copyright for the publications made accessible via the Queen's University Belfast Research Portal is retained by the author(s) and / or other copyright owners and it is a condition of accessing these publications that users recognise and abide by the legal requirements associated with these rights.

Take down policy

The Research Portal is Queen's institutional repository that provides access to Queen's research output. Every effort has been made to ensure that content in the Research Portal does not infringe any person's rights, or applicable UK laws. If you discover content in the Research Portal that you believe breaches copyright or violates any law, please contact openaccess@qub.ac.uk. 


\section{Spiral Antenna with Reconfigurable HIS using Liquid Crystals for Monopulse Radar Application}

\author{
Sarah Mohamad \\ Department of Electrical and Computer Engineering, \\ Kulliyyah of Engineering, \\ International Islamic University Malaysia (IIUM), \\ 53100 Kuala Lumpur, Malaysia. \\ smohamad@iium.edu.my
}

\author{
Robert Cahill \\ The Institute of Electronics, Communications and \\ Information Technology (ECIT), \\ Queen's University Belfast, \\ Northern Ireland Science Park, Queen's Road, \\ Belfast BT3 9DT, Northern Ireland, UK.
}

\begin{abstract}
In this paper, the design of an electronically reconfigurable ground plane composed of a high impedance surface (HIS) based on liquid crystals is presented and used as a backing structure for a two-arm Archimedean spiral antenna. The structure is used to provide electronic switching of two different shaped radiation patterns for monopulse radar application; 1) sum-pattern ( $\Sigma$-pattern), and 2) differencepattern ( $\Delta$-pattern). The antenna arrangement is shown to exhibit either the $\Sigma$ - or the $\Delta$-beam by changing the permittivity (and hence reflection phase) of the HIS reflector when a bias voltage is applied between the periodic array and ground plane. The HIS is demonstrated to resonate at $6 \mathrm{GHz}$, and numerical results are employed to investigate the performance of the HISbacked spiral arrangement, i.e. radiation pattern, impedance match, realized gain $(\Sigma$-pattern), and null depth $(\Delta$-pattern).
\end{abstract}

Keywords-spiral antenna; high impedance surface (HIS); liquid crystals; monopulse radar; direction-finding application.

\section{INTRODUCTION}

Planar four-arm spiral antennas have been used for wideband multimode direction-finding applications and satellite tracking devices [1]. These antennas are physically thin and can be mounted on airframes with backing cavities, which are normally added to provide unidirectional radiation. Dual-channel monopulse is usually achieved by employing $>2$ spiral arms, where an $n$-arm spiral can support $m=(n-1)$ modes of excitation; e.g. two-arm and four-arm spirals provide one and three useful modes $(m)$, respectively [1]. Although the four-arm spiral has been used to provide a monopulse pattern for many direction-finding applications, attempts to excite a two-arm spiral have also been carried out to generate sum and difference shaped beams from a single aperture. However, this method was found to be unsuccessful due to the presence of an unbalanced feed line which is caused by the in-phase current [1]. In this paper, a high impedance surface (HIS) based on liquid crystals is used as a means to electronically switch from a sum-pattern ( $\Sigma$-pattern) to a difference-pattern ( $\Delta$-pattern) when the structure is placed below a two-arm Archimedean spiral antenna. This occurs because it is possible to vary the phase of energy generated by the spiral in the lower hemisphere, which is reflected from the surface of the HIS and converted from left-hand circular polarization (LHCP) to righthand circular polarization (RHCP), or vice versa. By careful

This research was supported by International Islamic University Malaysia (IIUM) through IIUM Research Initiative Grant (RIGS15-134-0134). design, either constructive $(\Sigma)$ or destructive $(\Delta)$ interference may be obtained when the waves which are radiated in the forward hemisphere and the waves that are reflected from the ground plane are vertically summed. The electrical spacing between the spiral antenna and the surface of the HIS is selected to maximize the antenna performance, i.e. either to maximize the forward gain (constructive interference), or to obtain a null in the boresight direction (destructive interference). The path length phase $\phi_{\mathrm{PL}}$ is determined by the spacing between the antenna and HIS, and $\phi_{\mathrm{HIS}}$ is reflection phase attributed to the liquid crystals (LC)-based HIS which is frequency and bias-voltage dependent. The phase relationship given in Equation (1) and (2) must be satisfied;

Constructive $(\Sigma)$ interference;

$$
\phi_{\text {HIS }}(f, V)+2 \phi_{\mathrm{PL}}(f)=2 n \pi \quad n=0,1,2 \ldots
$$

Destructive $(\Delta)$ interference;

$$
\phi_{\mathrm{HIS}}(f, V)+2 \phi_{\mathrm{PL}}(f)=n \pi \quad n=1,3,5 \ldots
$$

\section{THEORY OF OPERATION}

Liquid crystals (LC) are widely used for display applications such as flat screen televisions, personal computer monitors and mobile phones [2]. Lately, this technology has also been employed to create reconfigurable microwave and millimeter wave devices and antennas by exploiting the unique dielectric anisotropic behavior of the nematic phase, which enables the permittivity of LC material to be varied when a small voltage is applied to the structure [3-6]. This is attributed to the orientation of the molecules in relation to the RF field direction; 1) perpendicular, $\varepsilon_{\perp}$ to the electric field (unbiased state), or 2) parallel, $\varepsilon_{/ /}$to the electric field (biased state), as stated in [4] for reflectarray antennas. In contrast, the two states relating to the electric field orientations is the opposite for a spiral antenna because the electric field vector is parallel to the aperture surface, unlike a reflectarray where it is perpendicular to the patch array [4]. The tunability of the HIS can be derived from Equation (3);

$$
\Delta \varepsilon_{e f f}=\varepsilon_{/ /}-\varepsilon_{\perp}
$$


where:

$\Delta \varepsilon_{\text {eff }}=$ change in permittivity of liquid crystals

$\varepsilon_{/ /}=$permittivity of liquid crystals (HIS) in unbiased state ( $\left.0 \mathrm{~V}\right)$

$\varepsilon_{\perp}=$ permittivity of liquid crystals (HIS) in biased state $(+\mathrm{V})$

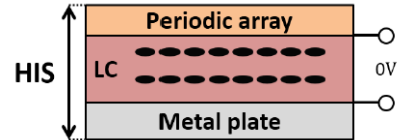

(a)

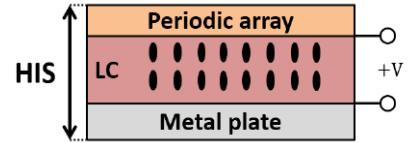

(b)
Fig. 1. Liquid crystal (HIS) molecular orientation; (a) unbiased state (0V), and (b) biased state $(+\mathrm{V})$.

The surfaces of the two electrodes, the periodic array and the metal plate which form the HIS, are coated with a very thin submicron polymer substrate which is rubbed with felt material to create microgrooves over the whole surface. This is used to align the molecules in the same orientation, parallel to the ground plane (Fig. 1(a)) [7]. A bias voltage applied across the cavity formed by the patterned FSS and the ground plane is used to align the LC molecules perpendicular to the two metal surfaces (Fig. 1(b)).

\section{DESIGN AND SimULATED RESUlTS}

A two-arm, four-turn Archimedean spiral antenna was designed to work in the 3-10 $\mathrm{GHz}$ frequency range [8] using CST MICROWAVE STUDIO software [9]. The outer and inner diameters are $60 \mathrm{~mm}$ and $4 \mathrm{~mm}$, respectively. The width and spacing between the conductors are both set to $1.65 \mathrm{~mm}$ to realize a self-complementary structure with an input impedance of $188 \Omega$ at all frequencies [10]. The spiral is fed in anti-phase at two excitation ports located $0.5 \mathrm{~mm}$ apart at the center of the structure. The geometry and dimensions of the antenna which was designed to generate predominantly RHCP signals is depicted in Fig. 2(a).

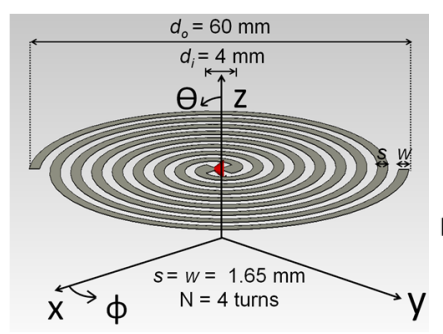

(a) (b)

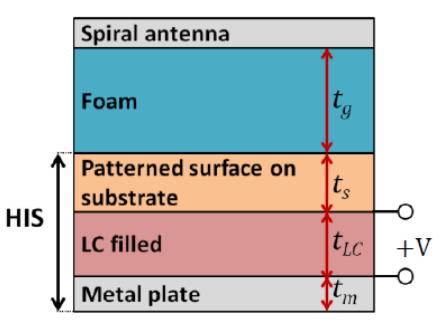

Fig. 2. (a) Archimedean spiral antenna geometrical parameters; outer diameter $d_{o}=60 \mathrm{~mm}$, inner diameter $d_{i}=4 \mathrm{~mm}$, spacing $s=1.65 \mathrm{~mm}$, width $w=1.65$ mm, number of turns $N=4$ [8], and (b) side view of spiral antenna on reconfigurable HIS based on liquid crystals with gap $t_{g}$, substrate $t_{s}=0.28$ $\mathrm{mm}$, substrate filled with liquid crystal $t_{L C}=500 \mu \mathrm{m}$, and metal $t_{m}=0.1 \mathrm{~mm}$.

Here, the HIS is demonstrated to resonate at $6 \mathrm{GHz}$. In the computer model, the periodic array of the HIS design was simulated on a $0.28 \mathrm{~mm}$ thick $\left(t_{s}\right)$ metal-backed Taconic CER-10 substrate with $\varepsilon_{r}=10$ and $\tan \delta=0.0035$. The substrate is separated from the ground plane by a $500 \mu \mathrm{m}$ thick cavity filled with GT3-23001 liquid crystals (Fig. 2(b)). The LC substrate, which is manufactured by Merck KGaA [2], is modelled for two states; 1) biased state $\left(\varepsilon_{\perp}=2.5, \tan \delta=\right.$ $0.0143)$, and 2$)$ unbiased state $(\varepsilon / /=3.3, \tan \delta=0.0038)$. The dimensions of an infinite array of Jerusalem cross slots which are patterned on the surface of the HIS are given in Fig. 3. A slot design was chosen for the HIS structure so that for practical implementation, the bias voltage can be applied across the cavity using one single excitation port on the surface of the patterned array. This is required to provide the reflection phase change for switching between the $\Sigma$ - and $\Delta$ patterns. A high permittivity substrate $\left(\varepsilon_{r}=10\right)$ was employed to reduce the physical size of the slot elements which are patterned across the whole surface of the HIS. This is required because electromagnetic coupling only occurs below the corresponding narrow active regions of the spiral antenna [11].

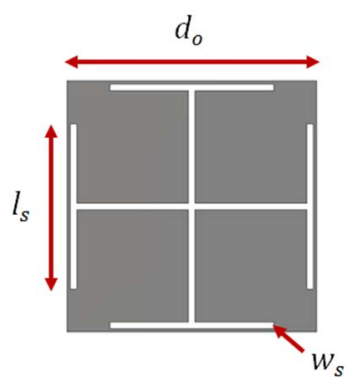

Fig. 3. The unit cell dimension of the $6 \mathrm{GHz}$ Jerusalem cross slots HIS; where $\operatorname{HIS}_{\phi=0^{\circ}}\left(d_{o}=7.6 \mathrm{~mm}, l_{s}=5 \mathrm{~mm}, w_{s}=0.2 \mathrm{~mm}\right)$, and $\operatorname{HIS}_{\phi=90^{\circ}}\left(d_{o}=7.5 \mathrm{~mm}, l_{s}=\right.$ $\left.4.6 \mathrm{~mm}, w_{s}=0.2 \mathrm{~mm}\right)$.
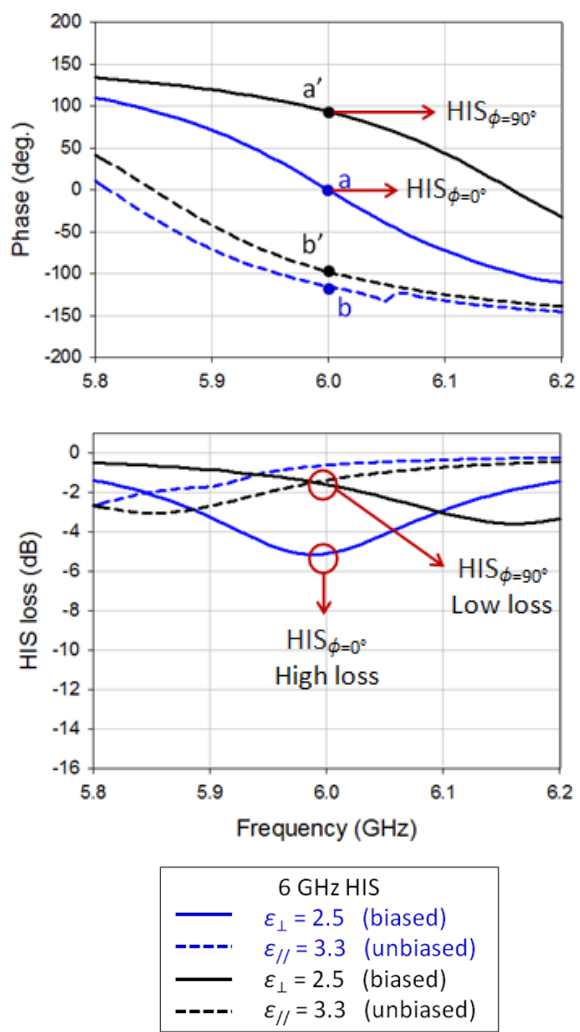

Fig. 4. Predicted reflection phase plots and loss of the $6 \mathrm{GHz}$ HIS reflector, HIS $_{\phi=0^{\circ}}$ and $\mathrm{HIS}_{\phi=90^{\circ}}$ (losses are included). 
The reflection phase plots and loss of the $6 \mathrm{GHz}$ HIS are depicted in Fig. 4. The $6 \mathrm{GHz}$ HIS is initially designed to operate at resonance $\left(\mathrm{HIS}_{\phi=0^{\circ}}\right)$ in the biased state with a permittivity of $\varepsilon_{\perp}=2.5$ (Fig. 4: Phase - blue solid curve). A phase shift $\approx 125^{\circ}$ (Fig. 4: Phase - point a to b) is produced when the substrate permittivity is set to the value corresponding to the unbiased state $\varepsilon_{/ /}=3.3$ (Fig. 4: Phase blue dashed curve). However, it is observed that the loss of the $6 \mathrm{GHz}$ at $\mathrm{HIS}_{\phi=0^{\circ}}$ is high with $5.2 \mathrm{~dB}$ (Fig. 4: HIS loss - blue solid curve). The high loss exhibited by the HIS at resonance $\left(\mathrm{HIS}_{\phi=0^{\circ}}\right)$ suppresses the amplitude of the waves reflected from the HIS. Therefore destructive interference is less complete, and the null depth (for $\Delta$-pattern) is significantly lower.
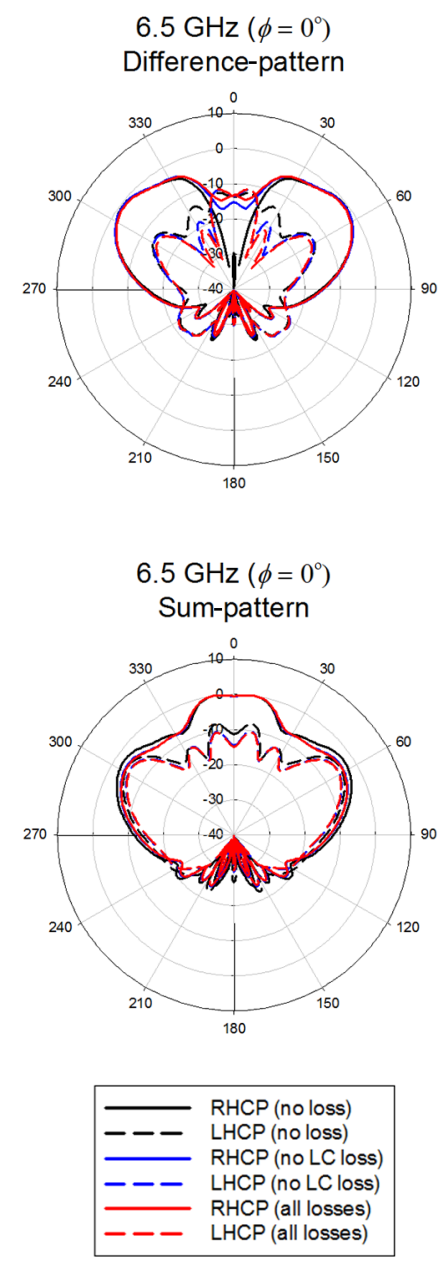

Fig. 5. Normalized predicted difference-pattern ( $\Delta$-pattern) and sum-pattern ( $\Sigma$-pattern) of the HIS-backed spiral antenna $\left(\mathrm{HIS}_{\phi=90^{\circ}}\right)$ at $6.5 \mathrm{GHz}$ with $\lambda / 8_{@ 6 \mathrm{GHz}}$ separation distance (losses are included).

Thus, the HIS is re-designed to operate with a reflection phase of $90^{\circ}$ i.e. HIS $_{\phi=90^{\circ}}$ (Fig. 4: Phase - black solid curve), in order to reduce the reflection loss which is observed at resonance i.e. $\mathrm{HIS}_{\phi=0^{\circ}}$ (Fig. 4: Phase - blue solid curve). The results show that at $6 \mathrm{GHz}$, the permittivity of the LC can be varied between $\varepsilon_{\perp}=2.5$ (biased state) and $\varepsilon_{/ /}=3.3$ (unbiased state) to obtain a phase range $\approx 180^{\circ}$ (Fig. 4 : Phase - point a' to b'), with lower HIS loss; i.e. $1.8 \mathrm{~dB}$. Following this, the $6 \mathrm{GHz} \mathrm{HIS}_{\phi=90^{\circ}}$ with dimensions of $225 \times 225 \mathrm{~mm}^{2}$ is placed $\lambda / 8 @ 6 \mathrm{GHz}$ below the spiral antenna to provide a $\Delta$-pattern and $\Sigma$-pattern, for the biased $\left(\varepsilon_{\perp}\right)$ and unbiased $\left(\varepsilon_{/ /}\right)$case, respectively. A null depth of $13.3 \mathrm{~dB}$ is obtained for the $\Delta$-pattern at $6.5 \mathrm{GHz}$ (frequency shift $\approx 8.3 \%$ ), and the $\Sigma$-pattern which is slightly distorted exhibits a maximum gain of $7.2 \mathrm{~dB}$ at boresight (Fig. 5) when all the losses are included in the numerical model. Fig. 6 shows that the predicted return loss (referenced to $188 \Omega$ ) of the spiral above the reconfigurable HIS arrangement is very well matched, corresponding to the sum and difference patterns with values of $>10 \mathrm{~dB}$ at the targeted frequency, with separation distance of $\lambda / 8 @ 6 \mathrm{GHz}$.

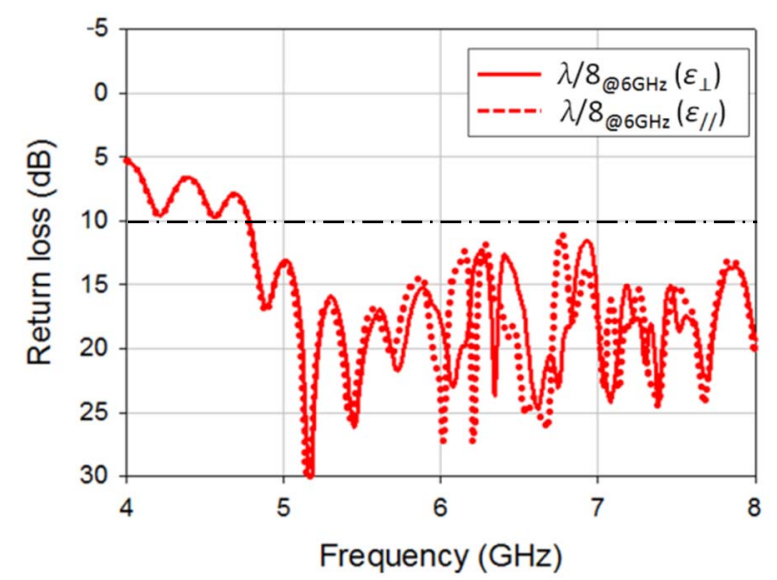

Fig. 6. Predicted return loss (ref: $188 \Omega$ ) of the HIS-backed spiral antenna $\left(\mathrm{HIS}_{\phi=90^{\circ}}\right)$ with $\lambda / 8_{@ 6 \mathrm{GHz}}$ separation distance (losses are included).

TABle I. Predicted Co-Polar Realized Gain ( $\left.\Sigma_{\text {pattern }}\right)$, Null DePth $\left(\Delta_{\text {PATtERN }}\right)$, Front-TO-BACK $(\mathrm{F} / \mathrm{B})$ RATIO $\left(\Sigma_{\text {PATTERN }}\right)$ AND BORESIGHT AXIAL RATIO $\left(\Sigma_{\text {PATTERN }}\right)$ OF THE HIS-BACKED SPIRAL ANTENNA $\left(\mathrm{HIS}_{\phi=90^{\circ}}\right)$ AT $6.5 \mathrm{GHz}$ WITH $4 / 8_{@ 6 \mathrm{GHz}}$ SEPARATION DISTANCE (LOSSES ARE INCLUDED).

\begin{tabular}{|c|c|c|c|c|}
\hline & $\begin{array}{c}\text { Realized } \\
\text { gain } \\
\left(\Sigma_{\text {pattern }}\right)\end{array}$ & $\begin{array}{c}\text { Null } \\
\text { depth } \\
\left(\Delta_{\text {pattern }}\right)\end{array}$ & $\begin{array}{c}\text { F/B ratio } \\
\left(\Sigma_{\text {pattern }}\right)\end{array}$ & $\begin{array}{c}\text { Axial } \\
\text { ratio } \\
\left(\Sigma_{\text {pattern }}\right)\end{array}$ \\
\hline $\begin{array}{c}\mathbf{6 . 5} \mathbf{~ G H z} \\
\left(\Delta_{\text {pattern }}\right) \\
\lambda / 8_{@ 6 G H z}\end{array}$ & - & 13.3 & - & - \\
\hline $\begin{array}{c}\mathbf{6 . 5} \mathbf{G H z} \\
\left(\Sigma_{\text {pattern }}\right) \\
\lambda / \mathbf{8}_{@ 6 \mathrm{GHz}}\end{array}$ & 7.2 & - & 29.6 & 3.3 \\
\hline
\end{tabular}

The numerical predictions are summarized in Table I. A $7.2 \mathrm{~dB}$ gain is predicted at $6.5 \mathrm{GHz}$. The gain increase, from that observed for a spiral in free space (i.e. $4.1 \mathrm{~dB}$ as in [8]), can largely be attributed to the backlobe suppression, which can be seen in Fig. 5. The front-to-back ratio (F/B) is $29.6 \mathrm{~dB}$, while the boresight axial ratio is $3.3 \mathrm{~dB}$ for the $\lambda / 8_{@ 6 \mathrm{GHz}}$ antenna/HIS separation distance. This result is further quantified by observing the predicted $3 \mathrm{D}$ co-polar (RHCP) 
beams generated by the spiral antenna in Fig. 7, which shows that the co-polar patterns at $6.5 \mathrm{GHz}$ are less symmetrical about boresight because of modal contamination that generates higher order mode radiation [12].
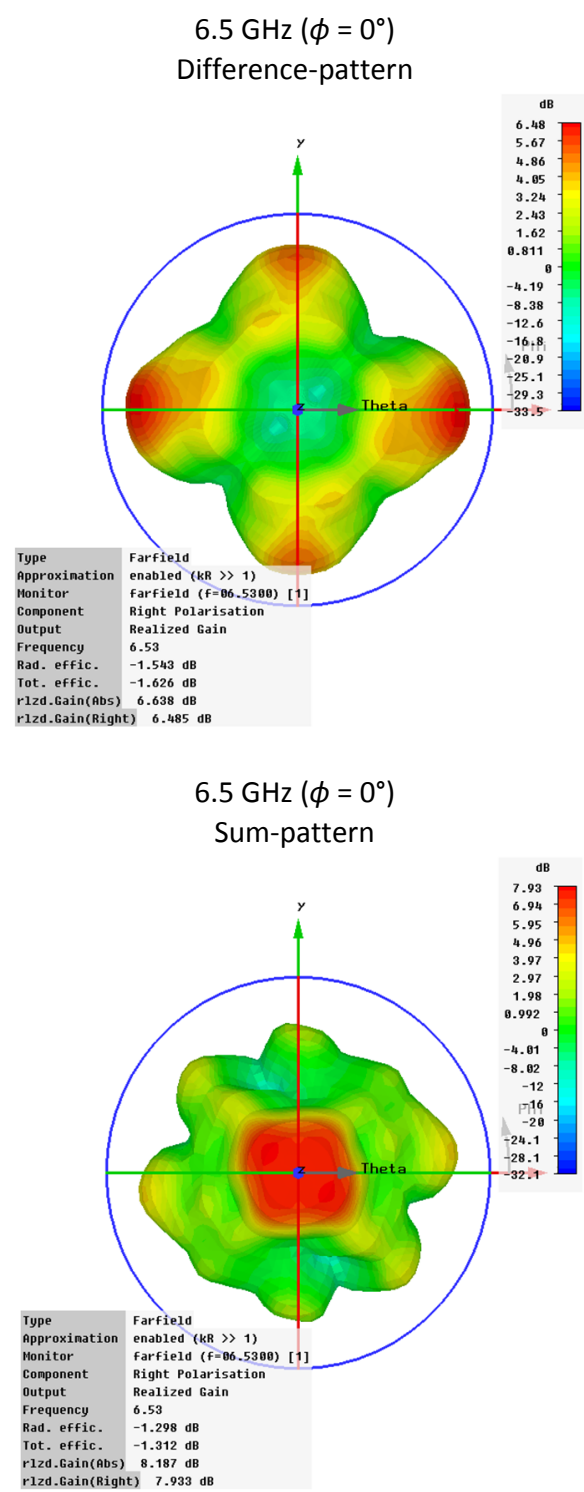

Fig. 7. Predicted 3D difference-pattern ( $\Delta$-pattern) and sum-pattern ( $\Sigma$-pattern) of the HIS-backed spiral antenna ( $\mathrm{HIS}_{\phi=90^{\circ}}$ ), showing co-polar (RHCP) beams, with boresight aligned along z-axis at $6.5 \mathrm{GHz}$ with $\lambda / 8_{066 \mathrm{Gz}}$ separation distance (losses are included).

\section{CONCLUSION}

In this paper, a study has been performed to show that an electronically reconfigurable ground plane that consists of a high impedance surface based on liquid crystals can be used to switch between a sum $(\Sigma-)$ and a difference $(\Delta-)$ shaped radiation pattern when this is placed below a two-arm Archimedean spiral antenna. For practical implementation, this can easily be done by varying the voltage between the metal patterned Jerusalem cross slot array and the ground plane, since this produces an electrostatic field in the cavity which controls the orientation of the liquid crystal molecules and hence the permittivity of the tunable material. GT3-23001 [2] liquid crystals with a permittivity and loss tangent of $\varepsilon_{\perp}=$ $2.5, \tan \delta=0.0143$ is used to model the fully biased case, whereas $\varepsilon_{/ /}=3.3, \tan \delta=0.0038$ is used for the unbiased case. Predicted results at $6.5 \mathrm{GHz}$ show that the HIS backed antenna arrangement can be designed to exhibit a deep null (for the $\Delta$-pattern) or a high gain in the boresight ( $\Sigma$-pattern) direction, when the permittivity of the substrate is changed. The study shows that the HIS should not be designed to operate at resonance $\left(\phi_{\mathrm{HIS}}=0^{\circ}\right)$, but at the frequency where $\phi_{\mathrm{HIS}}= \pm 90^{\circ}$, in order to reduce the loss and hence the magnitude of the reflected signals from the backing which is essential in order to provide a $\Delta$-pattern with a deep null. The feasibility study has successfully demonstrated that a very large change in the pattern shape is obtained using this type of reconfigurable HIS. Further work is required to develop this technology, for example to provide a deeper null, smoother radiation pattern and higher gain for the $\Delta$ - and $\Sigma$-patterns respectively, and the generation of more symmetrical patterns.

\section{REFERENCES}

[1] R. G. Corzine and J. A. Mosko, Four-Arm Spiral Antennas, First Edition, Artech House Publishers, 1990.

[2] "Merck," [Online]. Available: http://www.merck-performancematerials.com/en/display/applications/applications.html.

[3] R. Jakoby, P. Scheele, S. Muller, and C. Weil, "Nonlinear dielectrics for tunable microwave components," in 15th International Conference on Microwaves, Radar and Wireless Communications, pp. 369-378, 2004.

[4] M. Y. Ismail, W. Hu, R. Cahill, V. F. Fusco, H. S. Gamble, D. Linton, R. Dickie, S. P. Rea, and N. Grant, "Phase agile reflectarray cells based on liquid crystals," IET Microwaves, Antennas and Propagation, vol. 1, no. 4, pp. 809-814, 2007.

[5] W. Hu, R. Dickie, R. Cahill, H. Gamble, Y. Ismail, V. Fusco, D. Linton, N. Grant, and S. Rea, "Liquid crystal tunable $\mathrm{mm}$ wave frequency selective surface," IEEE Microwave Wireless Components Letters, vol. 17, no. 9, pp. 667-669, 2007.

[6] S. Christie, R. Cahill, N. Mitchell, Y. Munro, and A. Manabe, "Electronically scanned Rotman lens antenna with liquid crystal phase shifters," Electronics Letters, vol. 49, no. 7, pp. 445 - 447, 2013.

[7] N. Ito, K. Sakamoto, R. Arafune, and S. Ushioda, "Relation between the molecular orientations of a very thin liquid crystal layer and an underlying rubbed polyimide film," Journal of Applied Physics, vol. 88, no. 6, p. $3235,2000$.

[8] S. Mohamad, R. Cahill, and V. Fusco, "Selective high impedance surface active region loading of Archimedean spiral antenna," IEEE Antennas and Wireless Propagation Letters, vol. 13, pp. 810-813, 2014.

[9] “CST Microwave Studio," [Online]. Available: https://www.cst.com

[10] Y. Mushiake, "Self-complementary antennas," IEEE Antennas and Propagation Magazine, vol. 34, no. 6, pp. 23-29, 1992.

[11] S. Mohamad, R. Cahill, and V. Fusco, "Tri-band HIS backed spiral antenna for wireless LAN applications," Microwave and Optical Technology Letters, vol. 57, no. 5, pp. 1116-1121, 2015.

[12] S. Mohamad, R. Cahill and V. Fusco, "Design of a cavity backed spiral antenna with improved pattern symmetry," in Proc. $7^{\text {th }}$ European Conference on Antennas Propagation, pp. 3963-3967, 2013. 